\title{
Predictive ageing of elastomers: Oxidation driven modulus changes for polychloroprene
}

\author{
Le Gac Pierre-Yves ${ }^{1,{ }^{*}}$, Celina Mathew ${ }^{2}$, Roux Gérard ${ }^{3}$, Verdu Jacques ${ }^{4}$, Davies Peter ${ }^{1}$, \\ Fayolle Bruno ${ }^{4}$
}

1 IFREMER, Centre de Bretagne, Marine Structures Laboratory, CS 10070, 29280 Plouzane, France

${ }^{2}$ Sandia National Laboratories, Organic Materials Science Dept. 1853, Albuquerque, NM 87185, USA

${ }^{3}$ Thales Underwater Systems, TUS, route des Dolines, BP 157, 06903, Sophia-Antipolis Cedex, France

${ }^{4}$ PIMM, Arts et Métiers ParisTech, CNRS, CNAM 151 Bd de l'Hôpital, 75013 Paris, France

*Corresponding author : Pierre-Yves Le Gac, email address : pierre.yves.le.gac@ifremer.fr

\begin{abstract}
:
The oxidative ageing in the range of $60{ }^{\circ} \mathrm{C}-140{ }^{\circ} \mathrm{C}$ of sulfur vulcanized polychloroprene has been studied by FTIR spectroscopy (double bond consumption), modulus changes and oxygen absorption measurements. Experiments were carried out on thin films and thick samples to investigate both homogeneous and inhomogeneous (diffusion controlled) oxidation with the goal of establishing the underlying correlation between oxidative degradation chemistry and mechanical property changes. A correlation between oxidatively driven degradation chemistry and modulus is possible using the established approaches of rubber elasticity where an effective crosslinking yield due to double bond reactions is of the order of $30 \%$ for this material (i.e. the loss of 3 double bonds results in one effective crosslink associated with material hardening). It is then possible to predict modulus changes induced by oxidation for vulcanized and unstabilized polychloroprene rubber. A kinetic model is introduced with two propagation reactions (hydrogen abstraction and radical addition to double bonds) and two stabilization processes involving sulfur containing moieties from the vulcanization process. The kinetic scheme was solved and the relevant rate constants determined. This model can adequately predict modulus changes in films and thick samples as a function of time and spatially resolved.
\end{abstract}

Keywords: Polychloroprene, Ageing, Sulfur vulcanization, Oxidation, Kinetic modeling, Modulus changes 


\section{Introduction}

Soon after the theory of rubber elasticity was established, its potential to characterize network structural changes during polymer degradation, especially oxidation was investigated [1]. In principle, the approach is simple: the material is subjected to constant elongation and the resulting stress is recorded during its exposure in the degradative environment under study. The stress $\sigma$ for a stretching ratio $\lambda$ varies with crosslink density $(v)$, and the ideal rubber theory in its simplest form establishes a link between both quantities:

$\sigma=\operatorname{RT} \rho v\left(\lambda^{2}-\lambda^{-1}\right)$

where $\mathrm{R}$ is the gas constant and $\rho$ the polymer density.

From a practical point of view a lifetime is defined as the time to reach a limiting material property value for the application under consideration. Following Tobolsky's approach [1], we recognize that the rate of crosslink density change is the product of at least two terms ( $x$, number of crosslinking events and s, number of chain scission events). For instance in the case of "pure" crosslinking (no chain scission), it is possible to state:

$\mathrm{d} v / \mathrm{dt}=[\mathrm{d} v / \mathrm{dx}] .[\mathrm{dx} / \mathrm{dt}]$

where $\mathrm{x}$ is the number of crosslinking events.

The theory of rubber elasticity gives the first term, $d v / d x$, but the second term $d x / d t$ (i.e. crosslinking per time) must be obtained from chemical kinetics. Tobolsky and his group used the concepts of free radical auto-oxidation kinetics [2] to build a kinetic model in which initiation is due to unimolecular or bimolecular hydroperoxide decomposition [3]. However, while this model explains the autoaccelerated behavior of oxidation and can predict oxygen consumption (in thin samples) or hydroperoxide concentration, it does not predict crosslink density, which is essential for a link between mechanical properties and chemical parameters. Further, Tobolsky's initial model applied to saturated hydrocarbon polymers and does not take into account reactions of radical addition to existing double bonds, which play a key role in the oxidation of polydienic elastomers and other unsaturated polymers.

Surprisingly, Tobolsky's model was practically ignored during the last half century although it offers a significant level of complexity while still allowing for an analytical solution of the kinetic scheme. 
More recently [4], the problem was reexamined and a numerical solution was proposed to avoid the numerous simplifying hypotheses used by Tobolsky and coworkers. Using numerical tools also allows kinetic schemes of a considerably higher degree of complexity to be studied, for instance for unsaturated elastomers with antioxidants $[5,6]$.

In parallel, the research group at Sandia National Laboratories developed a simpler kinetic model with an analytical solution for a similar mechanistic scheme called the Basic Oxidation Scheme (also based on free radical auto-oxidation) [7]. With some assumptions, Gillen, Wise et al. proposed a kinetic model providing an analytical solution when coupling oxygen consumption rate and oxygen diffusion $[8,9]$. The main feature of this model is that the local oxidation rate is strongly dependent on the oxygen partial pressure. This aspect is fundamental to describe situations where oxidation is controlled by oxygen diffusion, i.e. a diffusion limited oxidation (DLO) regime for most materials at elevated temperatures. This approach was applied to nitrile and polychloroprene rubber oxidation $[10,11]$.

In a previous paper, we applied a mechanistic approach to an unvulcanized unstabilized unfilled polychloroprene (CR) [12]. An oxidation mechanistic scheme involving oxygen alkyl and peroxyl additions to double bonds was investigated and solved numerically without any simplifying hypotheses. In that work the rate constants involved in the kinetic model derived from the mechanistic scheme were interpreted with double bonds consumption kinetics. The present study expands this approach to model the oxidation of sulfur vulcanized polychoroprene at $100^{\circ} \mathrm{C}$ and establishes the foundation for a quantitative relationship between molecular modifications and modulus changes during the oxidation process. 


\section{Material and Methods}

\subsection{Material}

The elastomer under study is based on polychloroprene with a predominantly trans 1-4 structure, which is vulcanized by a sulfur system in the presence of accelerators ( $\mathrm{MgO}, \mathrm{ZnO}$ and stearic acid) and where sulfur vulcanization consumes existing double bonds. In the current formulation the total amount of inorganic materials is about $20 \%$ and no additional stabilizer was added. Its initial characteristics are given in Table 1. Double bond concentration is calculated by assuming that each monomer contains one double bond (monomer molar mass being equal to $88 \mathrm{~mol} / \mathrm{g}$ ), whereas sulfur content is determined by elemental analysis. The concentration of crosslink sites $(\mathrm{mol} / \mathrm{kg})$ is calculated from the measured rubber modulus ( $E$ in equation 3 ) by assuming that tetrafunctional crosslinks are predominant, where functionality $(f)$ is then equal to 4 and density $(\rho)$ is $1.245 \mathrm{~kg} / \mathrm{l}$ :

[crosslink sites] $=2 / f \quad E / 3 R T \rho$

\begin{tabular}{lcc}
\hline Species & Concentration $(\mathrm{mol} / \mathrm{kg})$ & Concentration $(\mathrm{mol} / \mathrm{l})$ \\
\hline Double bonds $^{\mathrm{a}}$ & 11.3 & 14 \\
\hline Sulfur $^{\mathrm{b}}$ & 0.36 & 0.45 \\
\hline Crosslink sites $^{\mathrm{c}}$ & 0.09 & 0.11 \\
\hline
\end{tabular}

Table 1: Initial characteristics of the polychloroprene material. Note: a) theoretical value calculated from the structure of the monomer unit; b) experimentally determined by elemental analysis; c) calculated from the rubber modulus.

The data shown in Table 1 require the following comments: Firstly, it is concluded that vulcanization has consumed only a small fraction of double bonds because the sulfur content is significantly lower than the total concentration of available double bonds. Therefore, the remaining double bond concentration in the elastomer is close to the theoretical value for unvulcanized polychloroprene. Secondly, by comparing the concentration of sulfur content and crosslink sites, each crosslink site involves a maximum of 4 sulfur atoms. Usually, sulfur vulcanization is associated with disulfide $\left(\mathrm{S}_{2}\right)$ bridges [13], but may involve longer sulfide bridges. Further, some local sulfur reaction may not effectively contribute to the elastomer network. In fact, it is expected that more sulfur than the theoretically required amount to form an ideal $S_{2}$ crosslink based network is necessary for any 
practical vulcanization process. Based on modulus and the perceived number of crosslinks according to rubber elasticity, the average molecular weight between crosslinks is $\sim 10 \mathrm{~kg} / \mathrm{mol}$.

\subsection{Exposure conditions and sample geometries}

Thermal oxidation was performed in Memmert ovens with forced convection at temperatures from 60 to $140^{\circ} \mathrm{C} \pm 2{ }^{\circ} \mathrm{C}$. Exposures were performed on both films $(100 \mu \mathrm{m})$ and thick samples $(4.8 \mathrm{~mm})$. The films were cut from bulk material cooled by liquid nitrogen with a Leica microtome.

\subsection{Chemical modifications}

Chemical modifications in aged samples such as double bond consumption and carbonyl formation were monitored by FTIR spectroscopy in transmission mode using thin films (about 10 microns thickness). FTIR analyses were performed on a Perkin Elmer Spectrum 2 with a resolution of $4 \mathrm{~cm}^{-1}$. Double bonds were carefully quantified as three peaks located between $1800 \mathrm{~cm}^{-1}$ and $1500 \mathrm{~cm}^{-1}$ and were fitted with Origin ${ }^{\circledR}$ software using a Gaussian peak for deconvolution purposes after baseline corrections. This deconvolution was explained in a previous study and yielded 3 peaks at 1790; 1725 and $1660 \mathrm{~cm}^{-1}$, with the peak positions not changing as a function of ageing state [14]. The area for the $1660 \mathrm{~cm}^{-1}$ peak (double bond) was then calculated and normalized to the unaged material. This ratio was then multiplied by the initial double bond concentration $\left([C=C]_{0}=14 \mathrm{~mol} / \mathrm{l}\right.$; see Table 1$)$ in order to obtain a quantitative value of changes in double bonds. Therefore, for a specific ageing duration the double bond concentration $[\mathrm{C}=\mathrm{C}]_{\mathrm{t}}$ is calculated as:

$[C=C]_{t}=A_{\text {aged sample }} / A_{\text {unaged sample }} *[C=C]_{0}$

\subsection{Oxygen consumption}

The consumption of oxygen during thermal ageing was determined using a commercial Oxzilla instrument with the previously described experimental approach [15]. The technique has been established as a routine analysis at Sandia National Laboratories with the instrumental response being calibrated using standard gas mixtures under a specific range setting. Total oxygen absorption in a sample and the resulting rates can also be compared against other materials with known oxidation rates. Known sample amounts (about $0.1 \mathrm{~g}$ at the highest and $1 \mathrm{~g}$ at the lowest temperature) were sealed at room temperature in ampoules of about $21 \mathrm{cc}$ volume and filled with air from a gas cylinder to provide a consistent reference air composition. In order to maintain air conditions of equal partial pressure at the elevated temperatures the samples were quickly vented 
when hot; hence ageing was always conducted at $630 \mathrm{~mm}-\mathrm{Hg}$ air pressure (ambient conditions in Albuquerque with $\mathrm{p}_{\mathrm{O} 2}=130 \mathrm{~mm}-\mathrm{Hg}$ ) independent of temperature. At each ageing temperature, the same sample was analyzed sequentially to obtain time-dependent results. It is an important requirement that the sample is sufficiently thin to avoid diffusion-limited oxidation conditions, so that a homogenous oxidation reaction occurs throughout the sample and the measured rate can be adequately expressed with respect to the total mass of the sample.

2.4 Modulus change during oxidation

Modulus change during oxidation was monitored in-situ on $100 \mu \mathrm{m}$ thick films using a DMA apparatus (TA Instruments DMA (2980)). Samples were tested in tensile mode at a frequency of $1 \mathrm{~Hz}$, with displacement amplitude of $5 \mu \mathrm{m}$ (0.05\%). Specimen dimensions were $10 \mathrm{~mm}$ length and $4 \mathrm{~mm}$ width.

Modulus profiles with a spatial resolution of $\sim 50 \mu \mathrm{m}$ were obtained on thick samples $(5 \mathrm{~mm})$ crosssections using a profiler apparatus, which monitors the penetration of a parabolic tip into a polymer sample. Penetration data are converted to inverse tensile compliance values, which approximate the modulus. The instrument and the methodology have been described in detail elsewhere [16].

\subsection{Oxygen permeability measurements}

Oxygen permeation experiments were performed on disk samples of approximately $64 \mathrm{~mm}$ diameter and $2 \mathrm{~mm}$ thickness using a custom-modifed, commercial Oxtran-100 coulometric permeation apparatus (Modern Controls MOCON, Inc., Mineapolis, MN, USA), which is based on an ASTM standard. To allow for high temperature analysis a modified sample holder was positioned in a laboratory oven. Oxygen permeability values ranged between 40 and $100^{\circ} \mathrm{C}$ are shown in Figure 1 , an activation energy value close to $39 \mathrm{~kJ} / \mathrm{mol}$ was determined. 


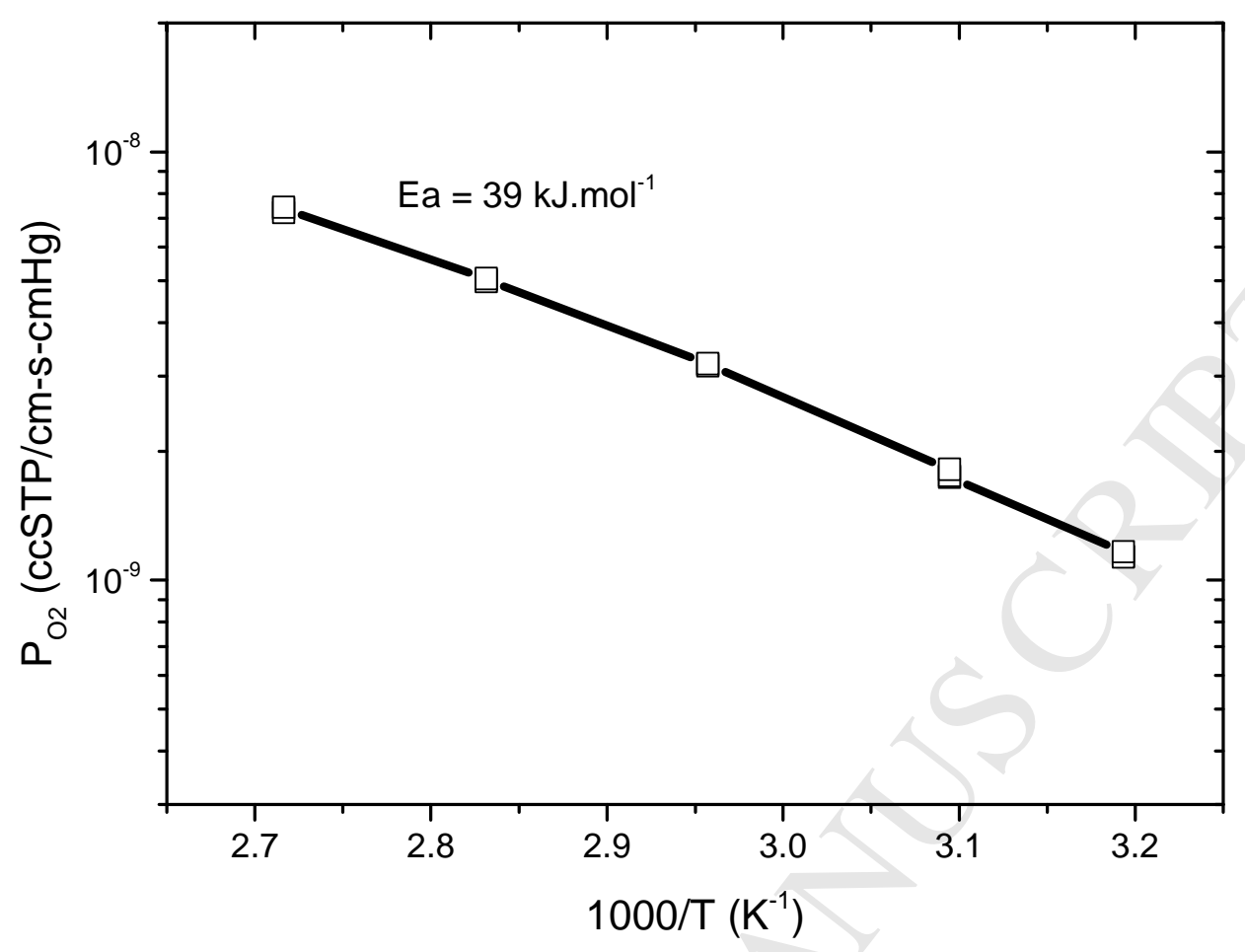

Figure 1 : Oxygen permeability coefficient as a function of temperature.

\section{Results}

3.1 Carbonyl and double bond consumption kinetics

As previously shown in the literature for polychloroprene degradation [14], oxidation leads to a variety of carbonyl species with absorption at $1725 \mathrm{~cm}^{-1}$ (ketones, acids) and $1790 \mathrm{~cm}^{-1}$ (attributed to acid chlorides). In the presence of metal oxides such as vulcanization accelerators some of these species such as acids or acid chlorides result in metal carboxylates absorbing at $1590 \mathrm{~cm}^{-1}$. Under these conditions the quantitative assessment of the absorbance changes of these species to determine an overall oxidation rate is highly complex and there is a risk of misinterpretation. In contrast, the peak for the double bonds at $1660 \mathrm{~cm}^{-1}$ shows little overlap and is a good indicator for the state of polymer oxidation (Figure 2). 

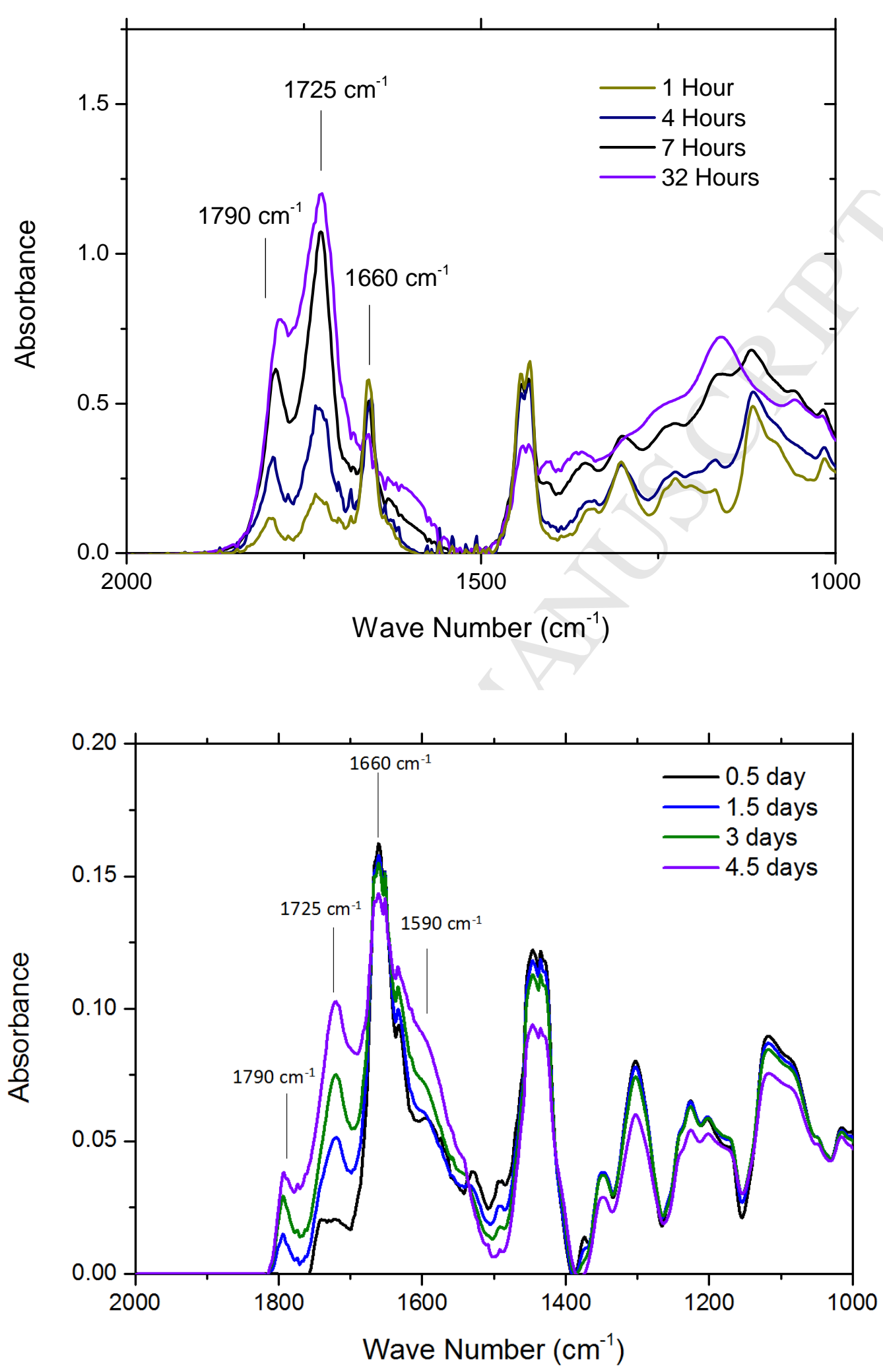

Figure 2 : Change in FTIR spectrum during thermal oxidation at $120^{\circ} \mathrm{C}$ of a) uncured [12] and b) vulcanized polychloroprene investigated in this study. 
As an example, Figure 3 shows the decay of double bond concentration as a function of ageing time at $100^{\circ} \mathrm{C}$ for both non-vulcanized and vulcanized polychloroprene (10 and 15 microns, respectively). The vulcanization additive or its reaction product clearly displays a strong stabilizing effect. Again, it is worth noting that $0.45 \mathrm{~mol}^{-\mathrm{I}^{-1}}$ of sulfur used in the formulation does not consume many of the double bonds during vulcanization. The observed oxidation rate decrease cannot be attributed to a decrease in double bond concentration due to vulcanization. It is, no doubt, due to the antioxidant effect of sulfides and disulfides present in the polymer [17]. Organic sulfides are well known to be antioxidants acting mainly by hydroperoxide decomposition.

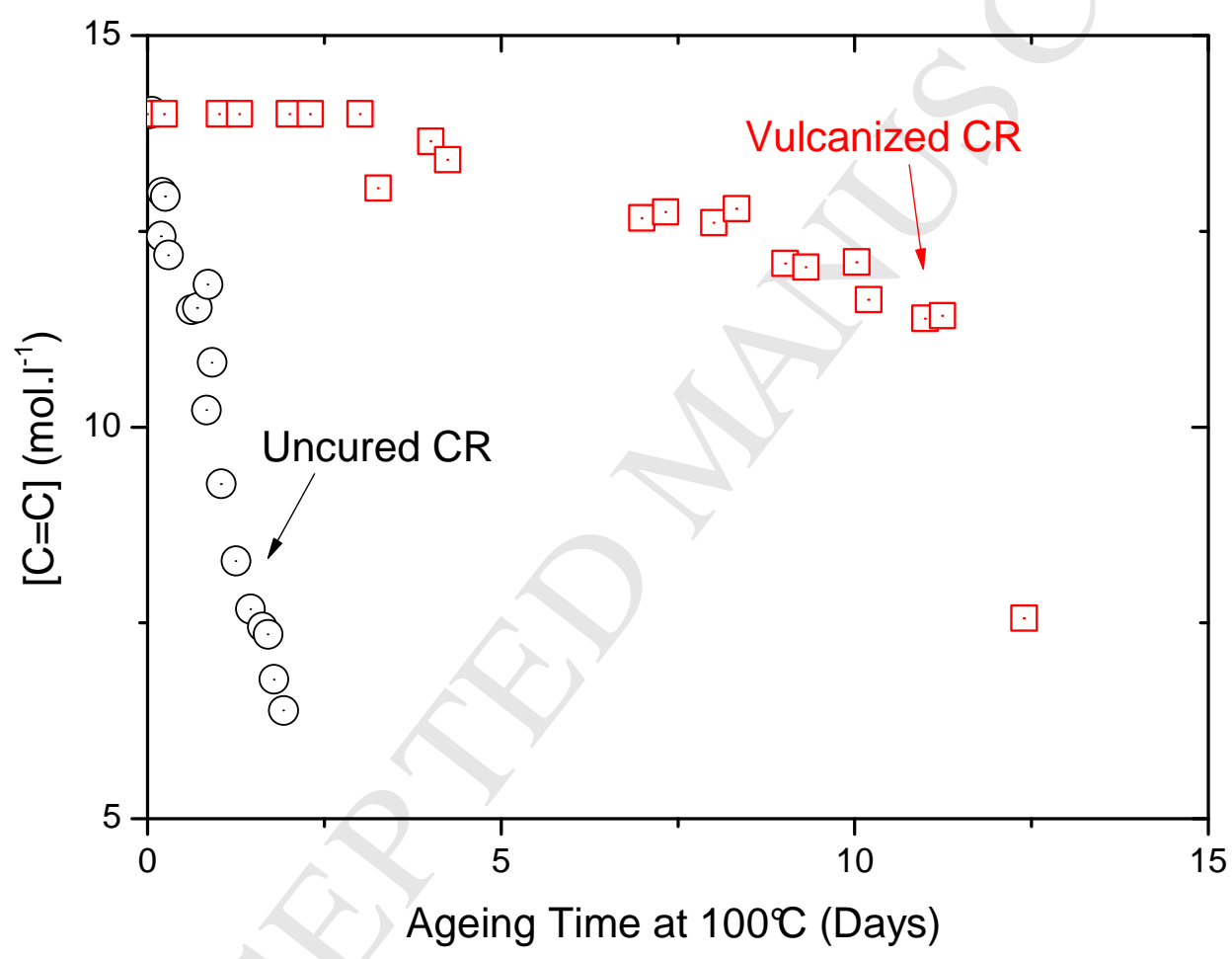

Figure 3 : Loss in double bond content for uncured and vulcanized polychloroprene during thermooxidative ageing at $100^{\circ} \mathrm{C}$ showing the increased stability of the cured material.

It is clear that the stabilizing effect of sulfur containing moieties must be taken into account in any kinetic model for this material. As previously proposed by Colin et al. [18], it was decided to represent stabilization by a sequence of two elementary processes, i.e. sulfide oxidation to sulfoxide and further sulfone formation:

$\mathrm{POOH}+\mathrm{R}-\mathrm{S}-\mathrm{R}--->\mathrm{POH}$ (or $\mathrm{P}=\mathrm{O})^{\circ} \mathrm{R}-\mathrm{SO}-\mathrm{R} \quad\left(\mathrm{k}_{\mathrm{S} 1}\right)$ 
$\mathrm{POOH}+\mathrm{R}-\mathrm{SO}-\mathrm{R}---->\mathrm{POH}($ or $\mathrm{P}=\mathrm{O})+\mathrm{R}-\mathrm{SO}_{2}-\mathrm{R}$

The exact process is likely more complex with the sulfone possibly transformed into more oxidized species, but a more complex mechanistic scheme would be out of reach of our numerical approach. It is suggested that the rate constant $k_{S 1}$ corresponds to a specific reaction while $k_{S 2}$ corresponds to an overall reaction kinetically equivalent to all secondary processes involving sulfur containing groups.

Similarly to the double bond consumption kinetics shown in Figure 3, carbonyl formation is observed as shown in Figure 4. For this figure the absorbance increase at $1725 \mathrm{~cm}^{-1}$ has been converted into concentration by using the Beer Lambert law with a molar absorptivity coefficient equal to 300 L/mol.cm [6]. The origin of carbonyls can be associated with multiple mechanisms involving chain scission, for example through hydroperoxide decomposition as mentioned previously (see also ref [12]). However, it is important to recognize that over the investigated time frame (10 days at $\left.100^{\circ} \mathrm{C}\right)$, the final carbonyl concentration is much lower in comparison with the effective double bond consumption. As a result, we can expect that crosslink events (as double bond consumption) are more frequent than chain scission events (carbonyl formation). This aspect will be confirmed later with respect to modulus changes.

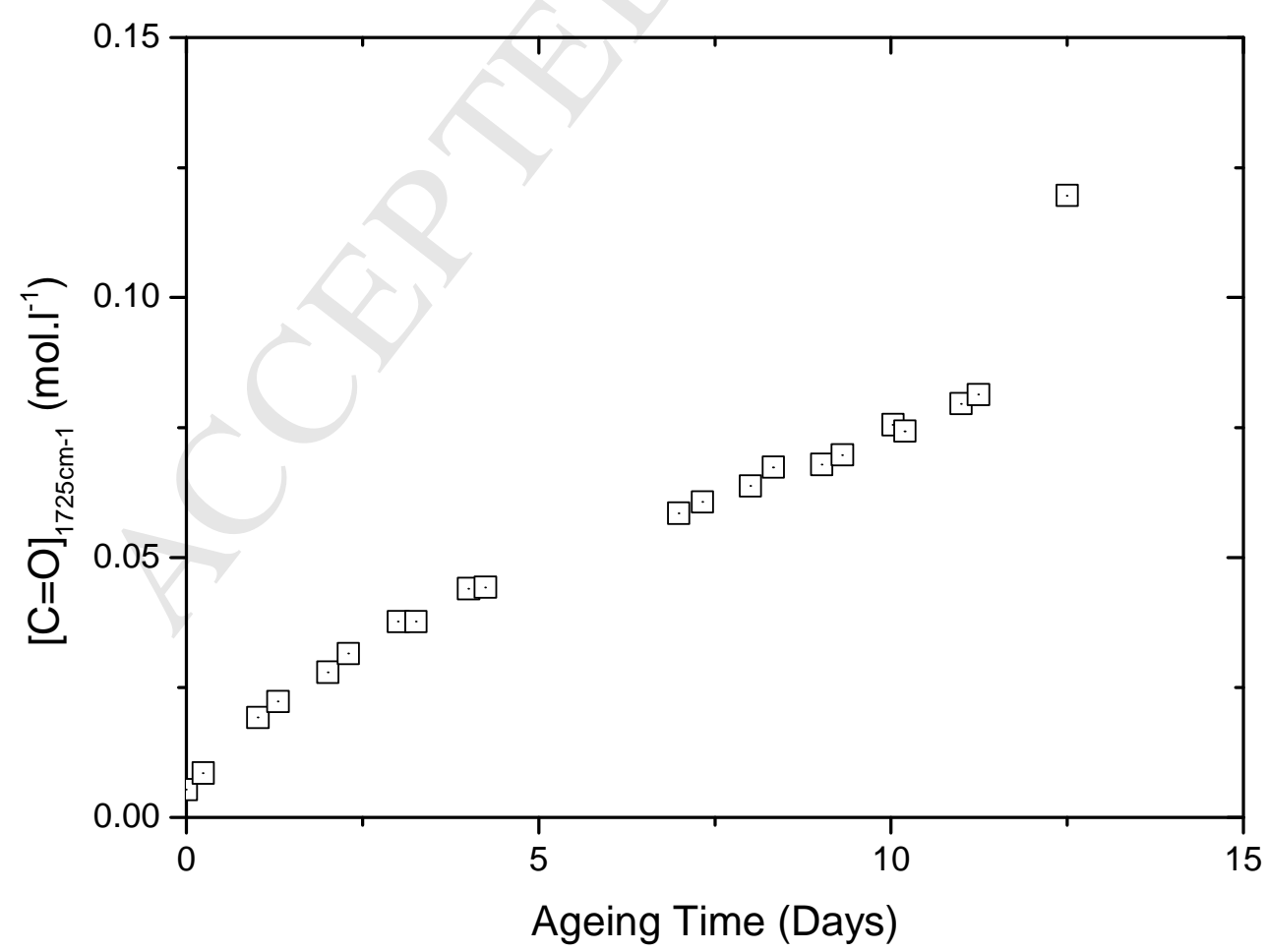


Figure 4: Carbonyl formation during thermal oxidation at $100^{\circ} \mathrm{C}$.

In order to assess the temperature influence on the double bond consumption kinetics, Figure 5 shows the double bond decay for several exposure temperatures between $60^{\circ} \mathrm{C}$ and $140^{\circ} \mathrm{C}$ for vulcanized polychloroprene. Since double bond consumption kinetics are clearly accelerated by the exposure temperature following an Arrhenius law (not shown here), an apparent activation energy value for the time required to consume $50 \%$ of double bonds can be determined as $\sim 72 \mathrm{~kJ} / \mathrm{mol}$. The value will be discussed and compared with other experimental feedback in the next sections. Subject to availability and some scatter in the experimental data, as well as some variance in the model parameters, these best fits and resulting curve shapes will not superpose perfectly in a timetemperature superposition, but average shift factors could easily be determined. A highest drop-off rate is seen for the $100^{\circ} \mathrm{C}$ data, where the final data point seems to more strongly dominate the fit of much of the earlier data (Figure 5), but this does not imply a deviation from the overall kinetic behavior with temperature.

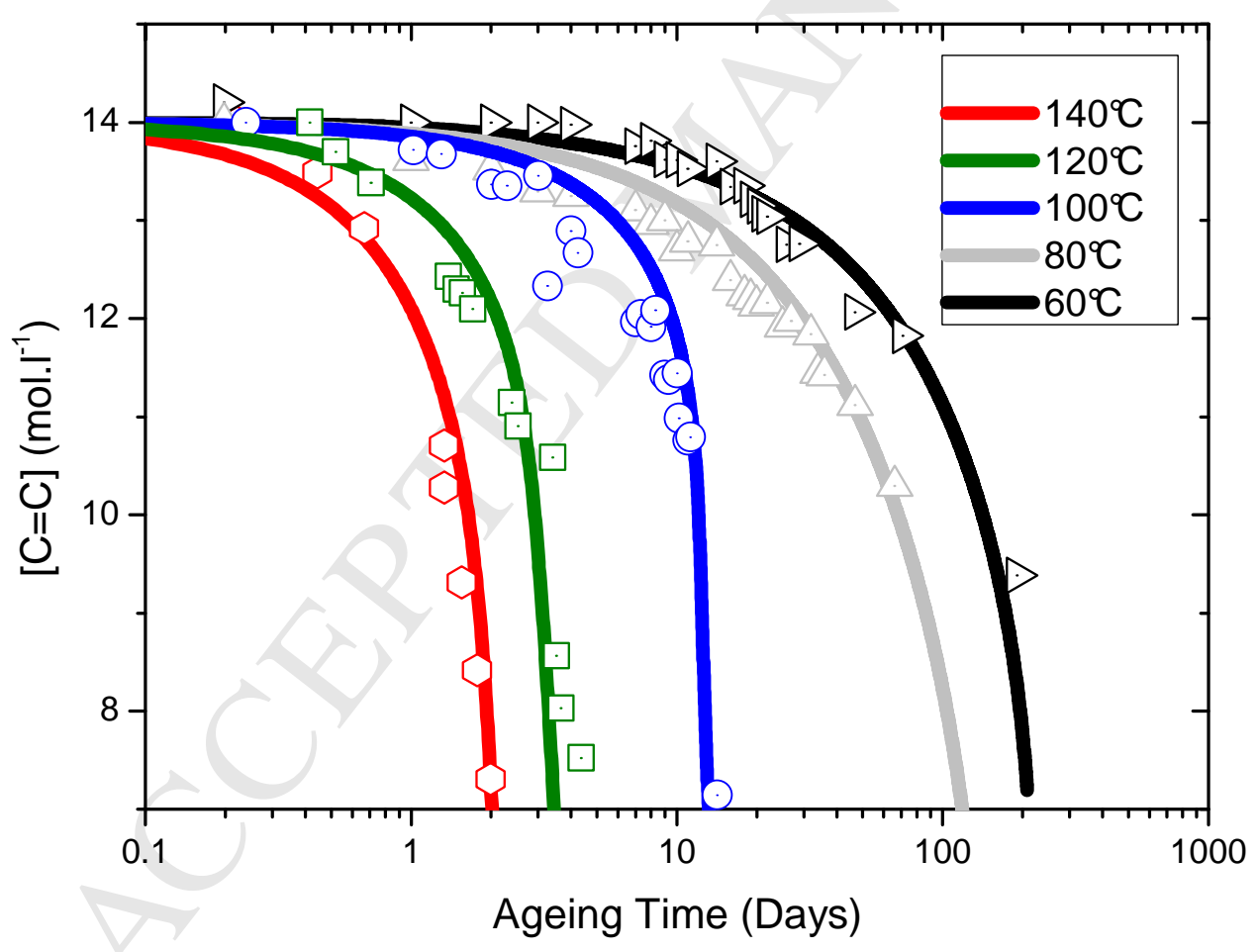

Figure 5: Effect of temperature on double bond consumption (symbols are experimental values and lines correspond to model fits discussed in 4.2).

\subsection{Oxygen absorption}


Comprehensive oxygen absorption measurements allow oxidation rate data for several isothermal conditions between 25 and $140^{\circ} \mathrm{C}$ to be determined. The oxidation rate dependence with temperature can be summarized in the Arrhenius plot shown in Figure 6. Experimental oxidation rates were averaged over time to get a mean value. Data obtained previously for a stabilized CR material have been added for comparison [11]. The oxidation rates plotted in Figure 6 are the average values measured over extended ageing times. The measured rates were found to be reasonably steady (subject to the intrinsic scatter in oxidation rate measurements) and did not display clear trends as a function of temperature and increasing oxidation level. We therefore decided that an Arrhenius plot using 'average rates' for the determination of Ea behavior was appropriate and a full time-temperature superposition for the underlying shift factor would not yield a better perspective.

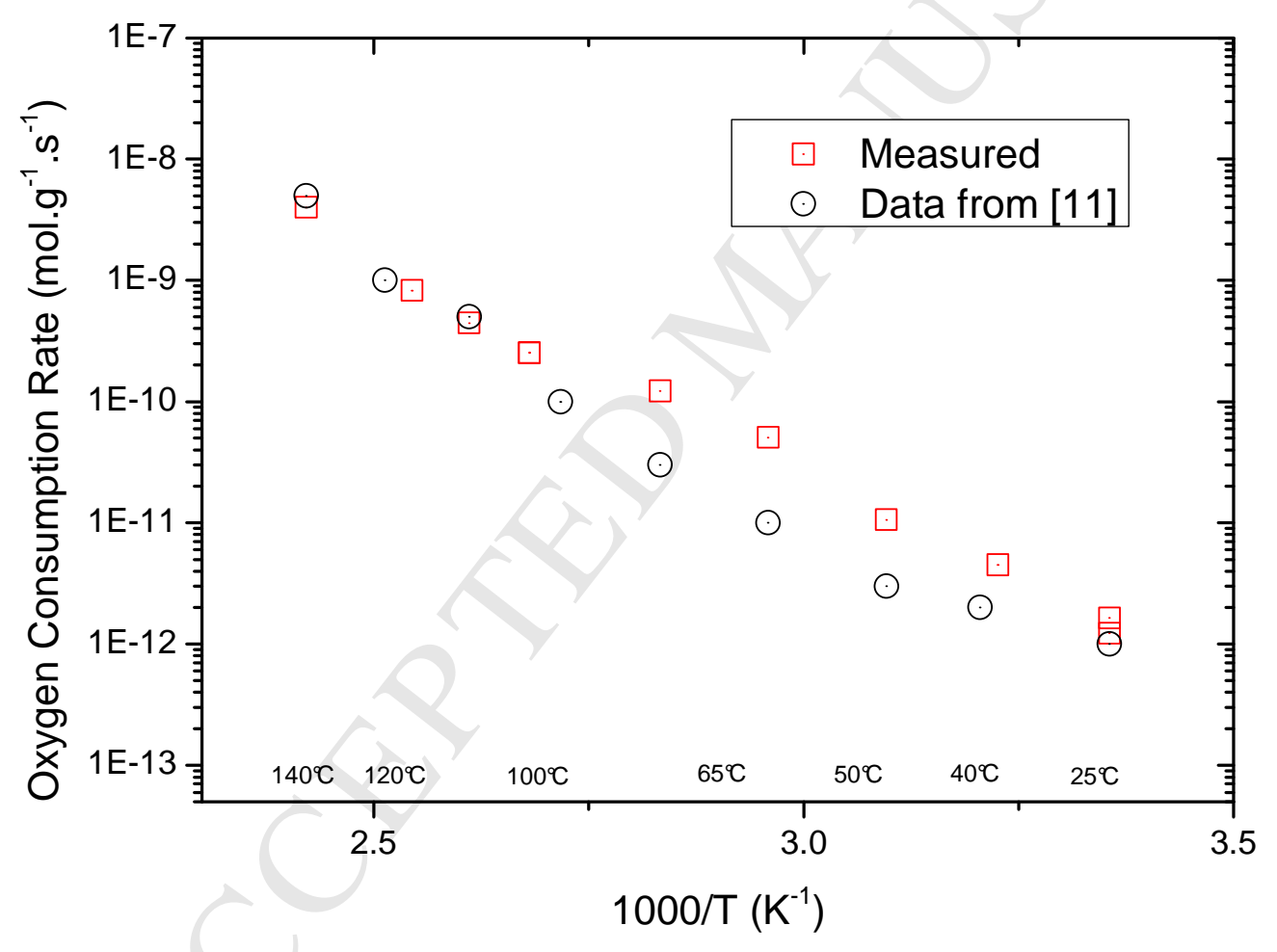

Figure 6 : Arrhenius plot of measured oxygen absorption rate in this study and previous data for another stabilized CR [11].

This figure allows the following comments:

- Data obtained from the present study show good Arrhenius behavior consistent with the observation for the double bond consumption rates in 3.1. Further, an activation energy of $66 \mathrm{~kJ} / \mathrm{mol}$ is determined which is similar to the value found for the double bond consumption rate $(72 \mathrm{~kJ} / \mathrm{mol})$. 
- A slight deviation can be witnessed between the data obtained from the present study and the data obtained by Celina in previous work, especially around the exposure temperature of 50 to $80^{\circ} \mathrm{C}$, perhaps for reasons of dissimilar stabilization.

\subsection{Modulus changes under non DLO condition}

The modulus of thin samples (100 $\mu \mathrm{m}$ thick films) was followed during the oxidation process for several isothermal conditions between $100^{\circ} \mathrm{C}$ and $140^{\circ} \mathrm{C}$. The modulus changes shown in Figure 7 were obtained continuously by performing the oxidation process under non DLO conditions in situ in a DMA. As expected, a significant modulus increase for all exposure conditions is observed confirming that oxidation promotes mostly a crosslinking process. A similar magnitude of material hardening under oxidative conditions was observed previously [11]. The apparent activation energy of this process by considering the time required to reach $25 \mathrm{MPa}$ is approximately $65 \mathrm{~kJ} / \mathrm{mol}$, a value similar to those for the double bond consumption or oxygen absorption processes. However, despite the crosslinking process being predominant, a chain scission process can occur in parallel since hydroperoxide $(\mathrm{POOH})$ decomposition can lead to carbonyl formation, or specific reactions between POOH with sulfur can lead to a loss of sulfur bridges. These aspects will be discussed later in 4.1.

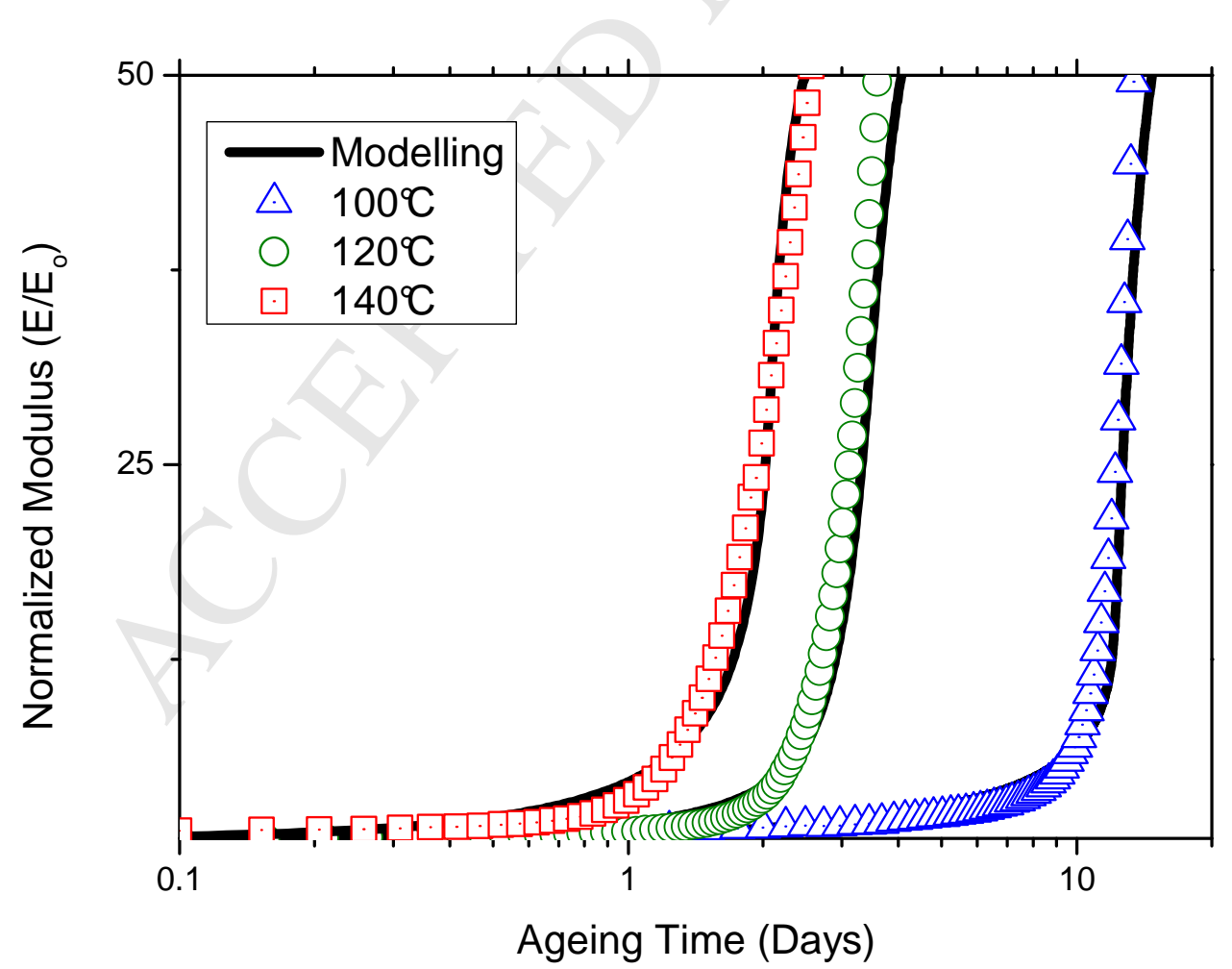


Figure 7: Effect of temperature on modulus increase under non DLO conditions (thin films) measured in-situ with DMA (symbols are experimental values and lines correspond to model based fits).

\subsection{Ageing under DLO condition}

Oxidation is diffusion controlled and oxidation depth profiles are expected to develop in thick samples. An oxidized sample then appears as a multilayer composite with a stiffness gradient across its thickness. It is therefore necessary to investigate modulus values as a function of thickness. The correlation between double bond consumption and modulus increase under DLO conditions can be examined, since experimental measurements of double bond concentration by IR in transmission on microtome sections and of local modulus by a micro-indentation method are possible with a resolution of 50 micrometers.

Figure 8 reports double bonds and modulus profiles for a sample exposed at $120^{\circ} \mathrm{C}$. These profiles reveal the presence of an oxidized skin of about one millimeter thickness, almost independent of the time of exposure while the core zone of about $3 \mathrm{~mm}$ thickness is practically unaffected. In the superficial zone of about $100 \mu \mathrm{m}$ thickness, double bonds have almost totally disappeared and modulus approaches values (about $1 \mathrm{GPa}$ ) typical of glassy polymers [19]. This behavior is consistent with prior observations for severe edge hardening [11].

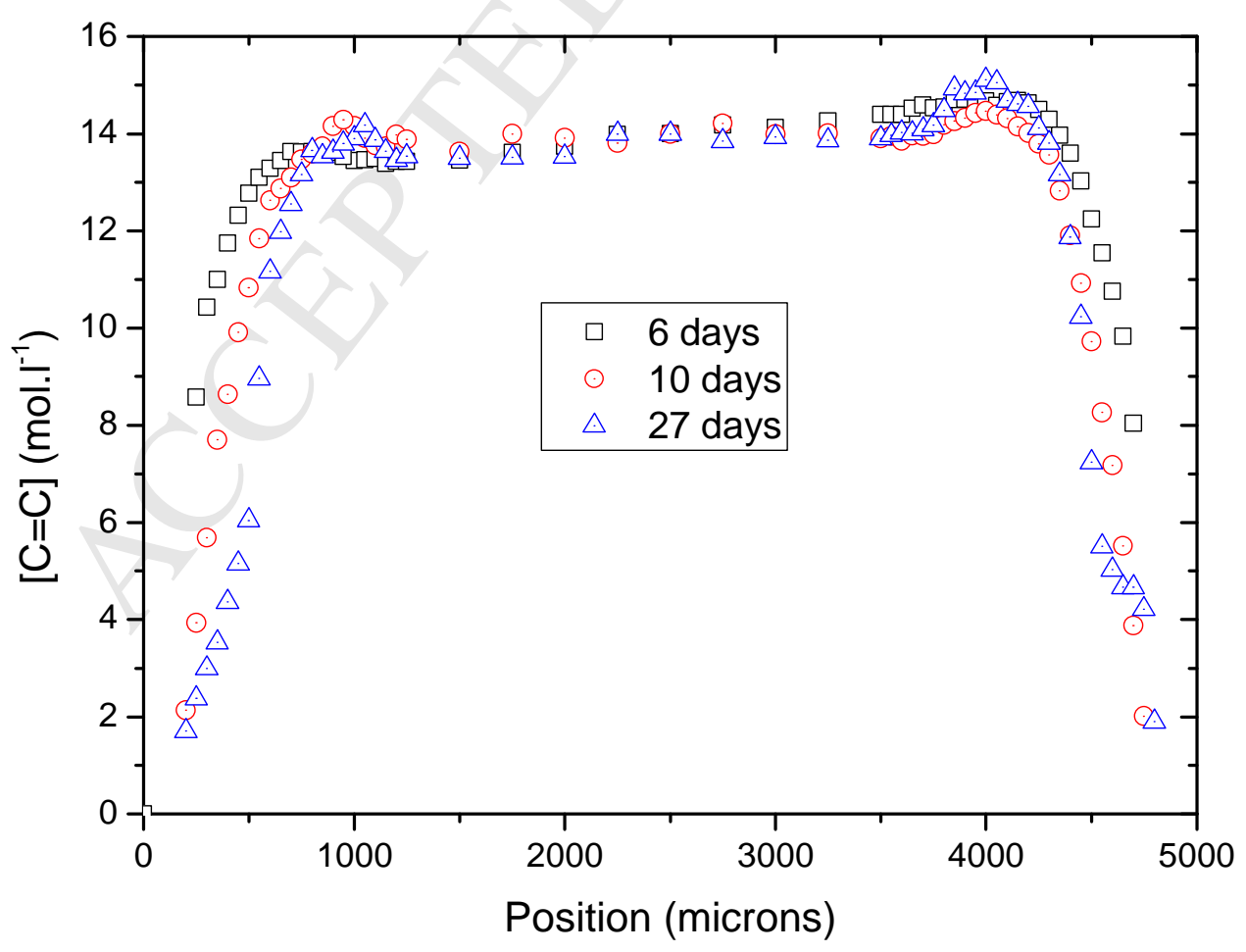




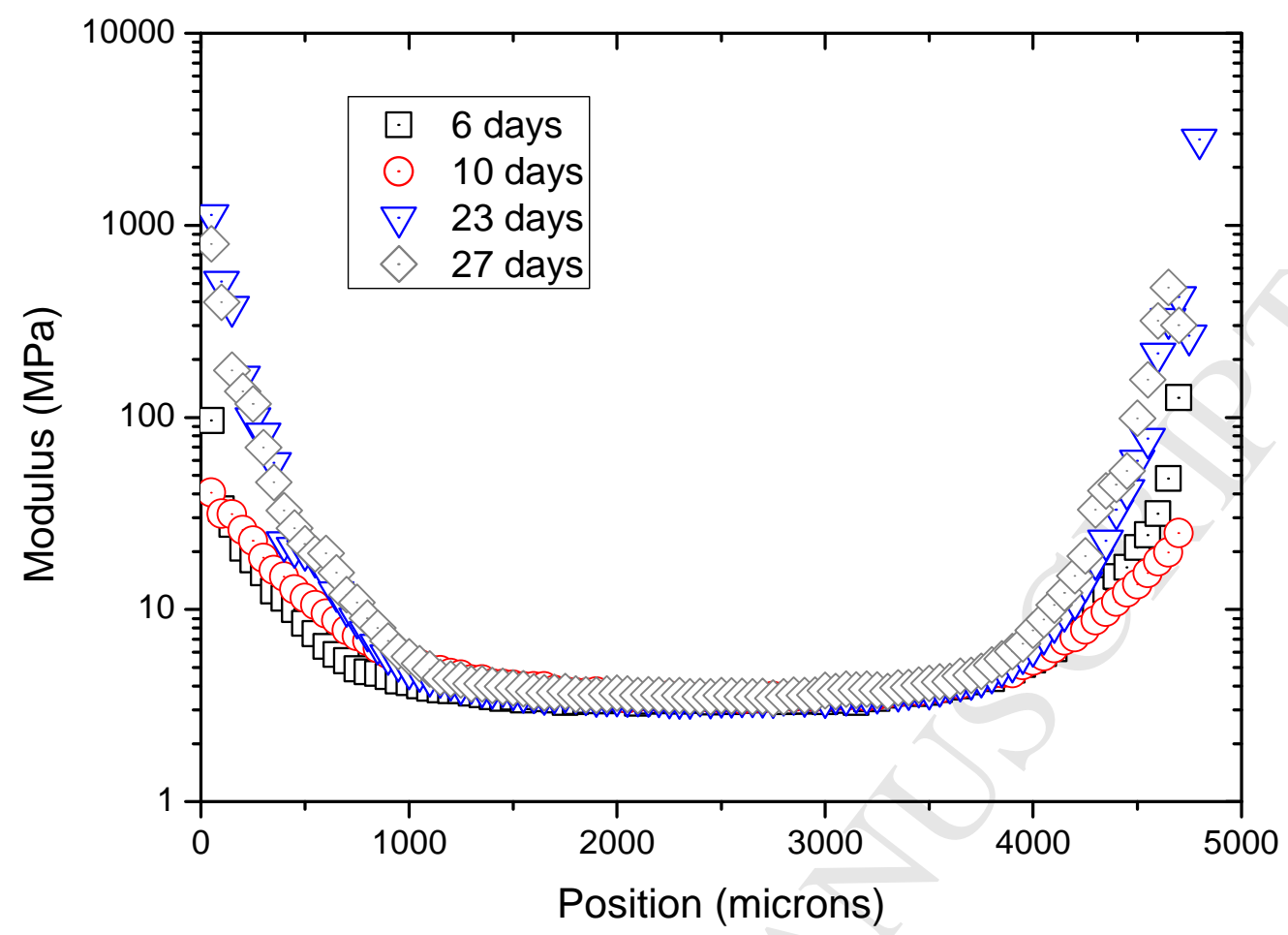

Figure 8 : Profile of double bonds (a) and modulus (b) through the thickness of a $4.8 \mathrm{~mm}$ thick sample during oxidation at $120^{\circ} \mathrm{C}$ in air.

\section{Discussion}

\subsection{Cross-correlation of modulus with double bond consumption}

In order to establish a quantitative correlation between oxidation level and modulus changes, we present the crosslink density data as a function of reacted double bonds for the exposures ranged between $100^{\circ} \mathrm{C}$ and $140^{\circ} \mathrm{C}$ in Figure 9 . The crosslink density values $(v)$ have been calculated from modulus values (from Figure 7) according to Eq. 3 and the reacted double bond concentration $\left(=\mathrm{F}_{0}-\right.$ $F(t)$ ) from Figure 3 by considering that modulus increase to a first degree is associated with a crosslink process induced by the addition reactions between radicals and double bonds. 


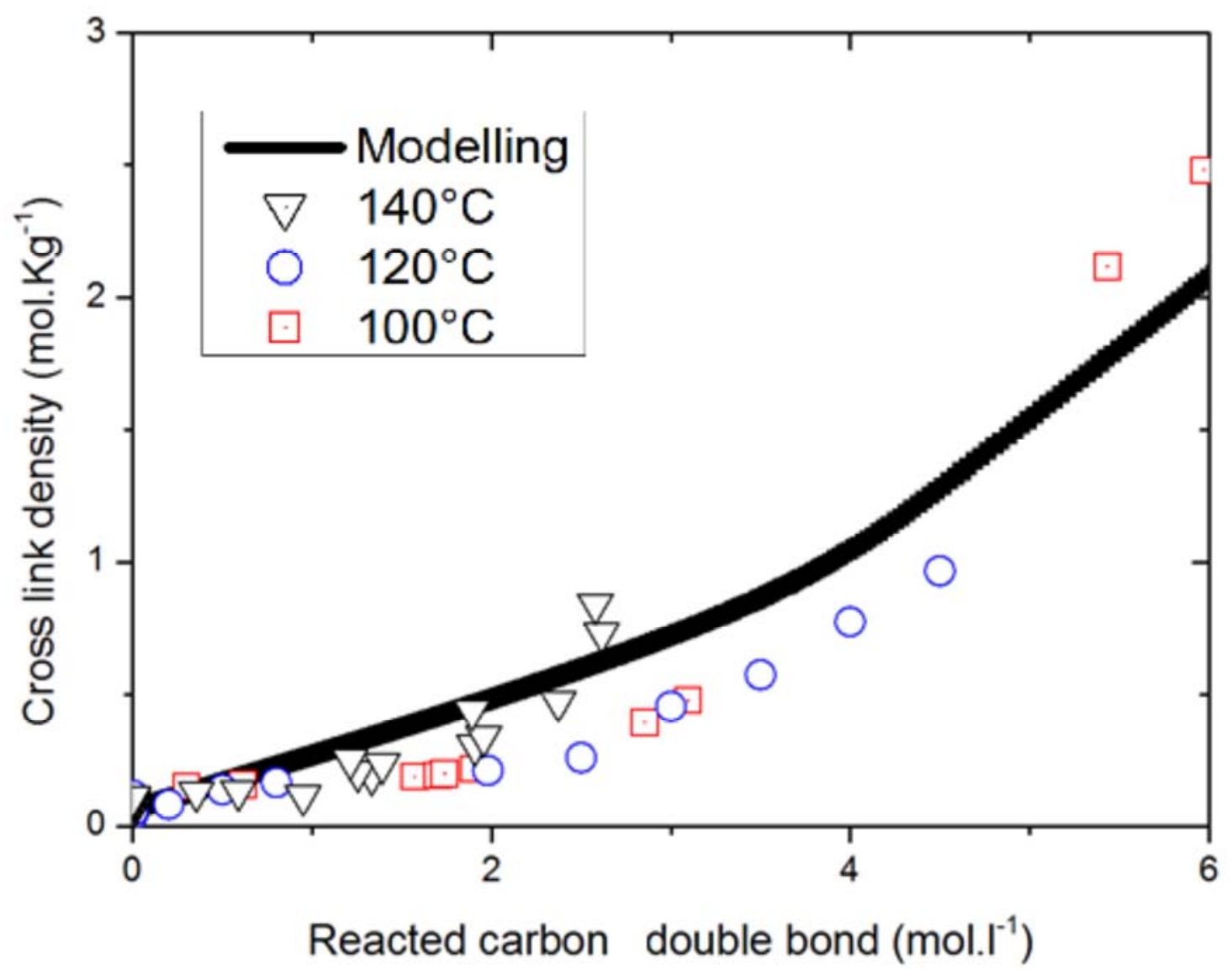

Figure 9 : Crosslink density as a function of reacted double bonds: experimental data were obtained for 100,120 and $140^{\circ} \mathrm{C}$ exposure temperatures, the solid curve shows the prediction from the kinetic model.

In order to predict modulus changes, a description of both crosslinking and chain scissions events is necessary. In fact, two different types of chains scission are considered here, the first one is random chain scission that occurs during the initiation step ( $\mathrm{POOH}$ decomposition in the oxidation scheme) named $s_{R}$ in table 2 . The second one is a selective scission that occurs during the reactions of POOH with sulfur, as a follow-up for sulfur bridge oxidation named $s_{s}$ in table 2.

In parallel, significant crosslinking occurs in the rubber during oxidation, where two types of crosslinking reactions can participate. The first and major one is the reaction of radicals with the double bond present in polychloroprene $\left(x_{F}\right.$ in table 2). The second one is associated with termination steps corresponding to reactions between alkyl and alkoxy radicals $\mathrm{s}, x_{\mathrm{T}}$ in table 2 .

These four modifications at the macromolecular scale can be represented and summarized in table 2 . 


Nature of the
reaction

Table 2: Summary of all macromolecular modifications considered here in order to predict modulus changes.

According to our mechanistic description, crosslinking events originate from macroradical additions to double bonds, but only a fraction $\tau$ of the consumed double bonds may lead to effective crosslinks directly responsible for hardening. Instead, some may undergo intramolecular additions or rearrangements with for instance epoxide formation [20]. The overall change of crosslink density $v$ (concentration of elastically active chains) at low conversions can be expressed as (3) where $s$ and $x$ are the numbers of chain scissions and crosslinking events described in table 2, respectively:

$$
v(t)=v_{0}-s_{R}(t)-2 s_{S}(t)+2 * \tau *\left(x_{F}(t)+x_{T}(t)\right)
$$

with $\tau$ a multiplier for crosslink effectiveness.

\subsection{Modulus prediction under non DLO conditions}

In order to validate this approach, the kinetics of chain scission and crosslinking events described in table 2 can be assessed by developing a kinetic model involving all the mechanisms associated with 
polychloroprene elastomer oxidation. For this purpose, the processes associated with sulfur stabilization are added to the previously established mechanistic approach for pure polychloroprene [12], leading to the following scheme (where $F$ is the double bond):

lb) $2 \mathrm{POOH} \rightarrow \mathrm{P}^{\circ}+\mathrm{POO}^{\circ}+\mathrm{s}_{\mathrm{R}} \quad\left(\mathrm{k}_{1 \mathrm{~b}}\right)$

II) $\mathrm{P}^{\circ}+\mathrm{O}_{2} \rightarrow \mathrm{POO}^{\circ} \quad\left(\mathrm{k}_{2}\right)$

III) $\mathrm{POO}^{\circ}+\mathrm{PH} \rightarrow \mathrm{POOH}+\mathrm{P}^{\circ} \quad\left(\mathrm{k}_{3}\right)$

F) $\mathrm{POO}^{\circ}+\mathrm{F} \rightarrow \mathrm{P}^{\circ}+x_{F} \quad\left(\mathrm{k}_{\mathrm{F} 1}\right)$

P) $\mathrm{P}^{\circ}+\mathrm{F} \rightarrow \mathrm{P}^{\circ}+x_{F} \quad\left(\mathrm{k}_{\mathrm{F} 2}\right)$

IV) $\mathrm{P}^{\circ}+\mathrm{P}^{\circ} \rightarrow$ inact. Prod. $+x_{T} \quad\left(\mathrm{k}_{4}\right)$

V) $\mathrm{P}^{\circ}+\mathrm{POO}^{\circ} \rightarrow$ inact. Prod. $+x_{T} \quad\left(\mathrm{k}_{5}\right)$

$\mathrm{VI}) \mathrm{POO}^{\circ}+\mathrm{POO}^{\circ} \rightarrow$ inact prod. $+\mathrm{O}_{2}+x_{T} \quad\left(\mathrm{k}_{6}\right)$

S1) $\mathrm{POOH}+\mathrm{R}-\mathrm{S}-\mathrm{R} \rightarrow \mathrm{POH}($ or $\mathrm{P}=\mathrm{O})+\mathrm{R}-\mathrm{SO}-\mathrm{R}+\mathrm{S}_{\mathrm{S}}\left(\mathrm{k}_{\mathrm{S} 1}\right)$

S2) $\mathrm{POOH}+\mathrm{R}-\mathrm{SO}-\mathrm{R} \rightarrow \mathrm{POH}($ or $\mathrm{P}=\mathrm{O})+\mathrm{R}-\mathrm{SO}_{2}-\mathrm{R}+\mathrm{s}_{\mathrm{S}} \quad\left(\mathrm{k}_{\mathrm{S} 2}\right)$

It is assumed that all initially present sulfur atoms are active in $\mathrm{POOH}$ reduction (reactions $\mathrm{S}_{1}$ and $\mathrm{S}_{2}$ ). To confirm the proposed values of $k_{\mathrm{S} 1}$ and $\mathrm{k}_{\mathrm{S} 2}$ determined here, a specific study investigating the influence of sulfur content on the oxidation rate could be important.

The set of differential equations derived from this scheme, i.e. the 'kinetic model', is resolved using Matlab software. It is noteworthy, that all the rate constants except $k_{s 1}$ and $k_{s 2}$ have been previously determined [12]. The remaining rate constants are determined from the current experimental data for the double bond decay using the kinetic model in an inverse approach. An optimized data fit yields the underlying rate constants. Figure 5 shows the modeled double bond decay for several exposure temperatures and Figure 10 presents the Arrhenius plot of the embedded $k_{\mathrm{s} 1}$ and $k_{\mathrm{s} 2}$ values obtained by the inverse approach through model fits. 


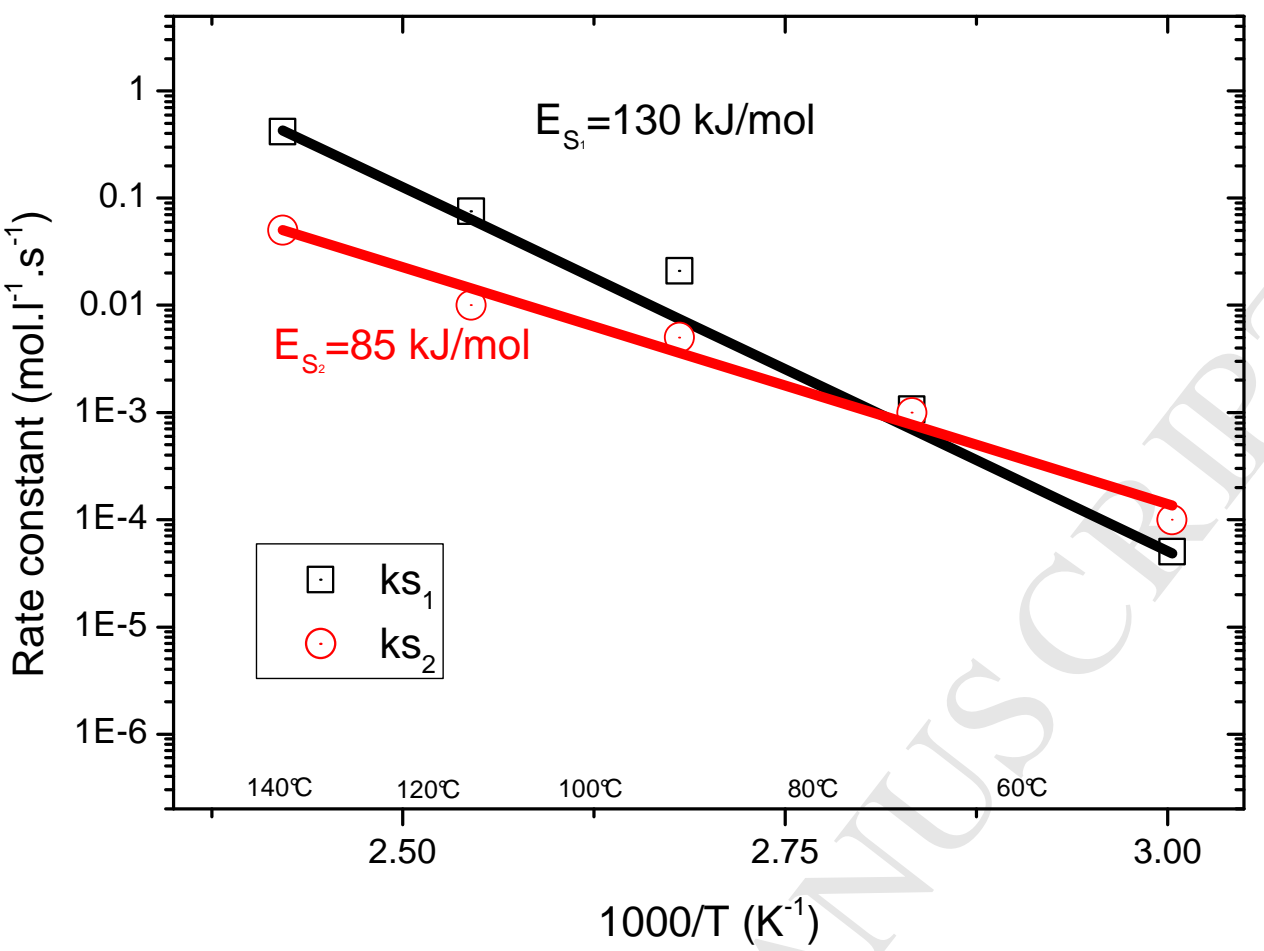

Figure 10: Arrhenius plot for the rate constants of the reactions involving sulfur obtained between 140 and $60{ }^{\circ} \mathrm{C}$.

Both rate constants seem to obey linear Arrhenius behavior, i.e. they behave as true elementary rate constants. The Ea's are $130 \mathrm{~kJ} / \mathrm{mol}$ for $\mathrm{k}_{\mathrm{s} 1}$ and $85 \mathrm{~kJ} / \mathrm{mol}$ for $\mathrm{k}_{\mathrm{s} 2}$ which is in agreement with those for sulfide oxidation [21] in various hydrocarbon polymers, or phosphites in PP [22], as well as for the polymer oxidation process.

In the case of homogeneous ageing, the kinetic scheme (shown at the beginning of this section) then allows the concentration of reactive species: $\mathrm{P}^{\circ}, \mathrm{POO}^{\circ}, \mathrm{POOH}, \mathrm{PH}, \mathrm{RSR}$ and $\mathrm{RSOR}$ to be predicted as a function of exposure time. According to the kinetic description key dependencies related to the overall network state formation (scission and crosslinking) can be derived:

$\begin{aligned} \frac{d s_{R}}{d t} & =k_{1 b}[\mathrm{POOH}]^{2} \\ \frac{d s_{S}}{d t} & =k_{S 1}[\mathrm{POOH}][R S R]+k_{S 2}[\mathrm{POOH}][\mathrm{ROSR}]\end{aligned}$

And

$\frac{d x_{F}}{d t}=k_{F 1}[F]\left[P O O^{\circ}\right]+k_{F 2}[F]\left[P^{\circ}\right]$ 
$\frac{d x_{T}}{d t}=\delta k_{4}\left[P^{\circ}\right]^{2}+\delta k_{5}\left[P^{\circ}\right]\left[P O O^{\circ}\right]+\delta k_{6}\left[P O O^{\circ}\right]^{2}$

Where $\delta=0.5$ in this case, for details see [12].

The equation (3) associated to (4-7) describing the overall network state formation (scission and crosslinking) allows crosslink density $(v)$ to be predicted as a function of reacted double bonds. A good agreement is then observed in Figure 9 provided the value of $\tau$ (a multiplier for crosslink effectiveness) was chosen to be 0.35 independent of temperature. In other words, only one third of the reacted double bonds participate in effective crosslinks for elastomer hardening (presumably tetrafunctional in this study).

As discussed earlier the equilibrium stress is proportional to the concentration of elastically active chains. For small elongations, classical approximations derive a very simple expression for the tangent (Young's) modulus $E(t)=3 R T \rho v(t)$. The resulting modulus predictions from modeled crosslink density are compared to experimental data in Figure 7 (i.e. the modeled curves). The model predicts the shape of the kinetic curves and the order of magnitude of modulus values very well, without any adjustment for modulus values up to $50 \mathrm{MPa}$.

\subsection{Modulus prediction under DLO conditions}

The model used for thick samples is exactly the same as for homogeneous oxidation except for the fact that the oxygen concentration depends on time due to both consumption by the oxidation process and increase due to diffusion from the exterior. These phenomena can be written in mathematical terms using the following equation which has been added to the model described previously [4]:

$\frac{d\left[O_{2}\right]}{d t}=-k_{2}\left[O_{2}\right]\left[P^{\circ}\right]+k_{6}\left[P O O^{\circ}\right]^{2}+D \cdot \frac{d^{2}\left[O_{2}\right]}{d z^{2}}$

Where $D$ is the oxygen diffusion coefficient $\left(\right.$ in $\left.\mathrm{m}^{2} . \mathrm{s}^{-1}\right),\left[\mathrm{O}_{2}\right]$ is the oxygen concentration, $z$ the layer depth in the sample thickness and $t$ time.

Classical permeability $(P)$ measurements allowed $P$ values to be determined at several temperatures in the domain of interest. An Arrhenius plot of these values is shown in Figure 1. Since $P=D . S$, and the solubility coefficient $S$ is of the order of $3.10^{-8} \mathrm{~mol}^{-1} \mathrm{~L}^{-1} \mathrm{~Pa}^{-1}[23]$ with an almost zero activation energy, the diffusion coefficient then follows $D=D_{0} \exp \frac{E_{D}}{R T}$ with $D_{0}=3.10^{-4} \mathrm{~m}^{2} \mathrm{~s}^{-1}$ and $E_{D}=39$ 
$\mathrm{kJ} / \mathrm{mol}$. The $D$ value at $120^{\circ} \mathrm{C}, 1.910^{-9} \mathrm{~m}^{2} \mathrm{~s}^{-1}$ is in good agreement with literature values [10]. After incorporation of Equation (7) in the kinetic scheme and solving in time and space ( $z$ ), oxidation profiles can then be predicted. An example is given in Figure 11.

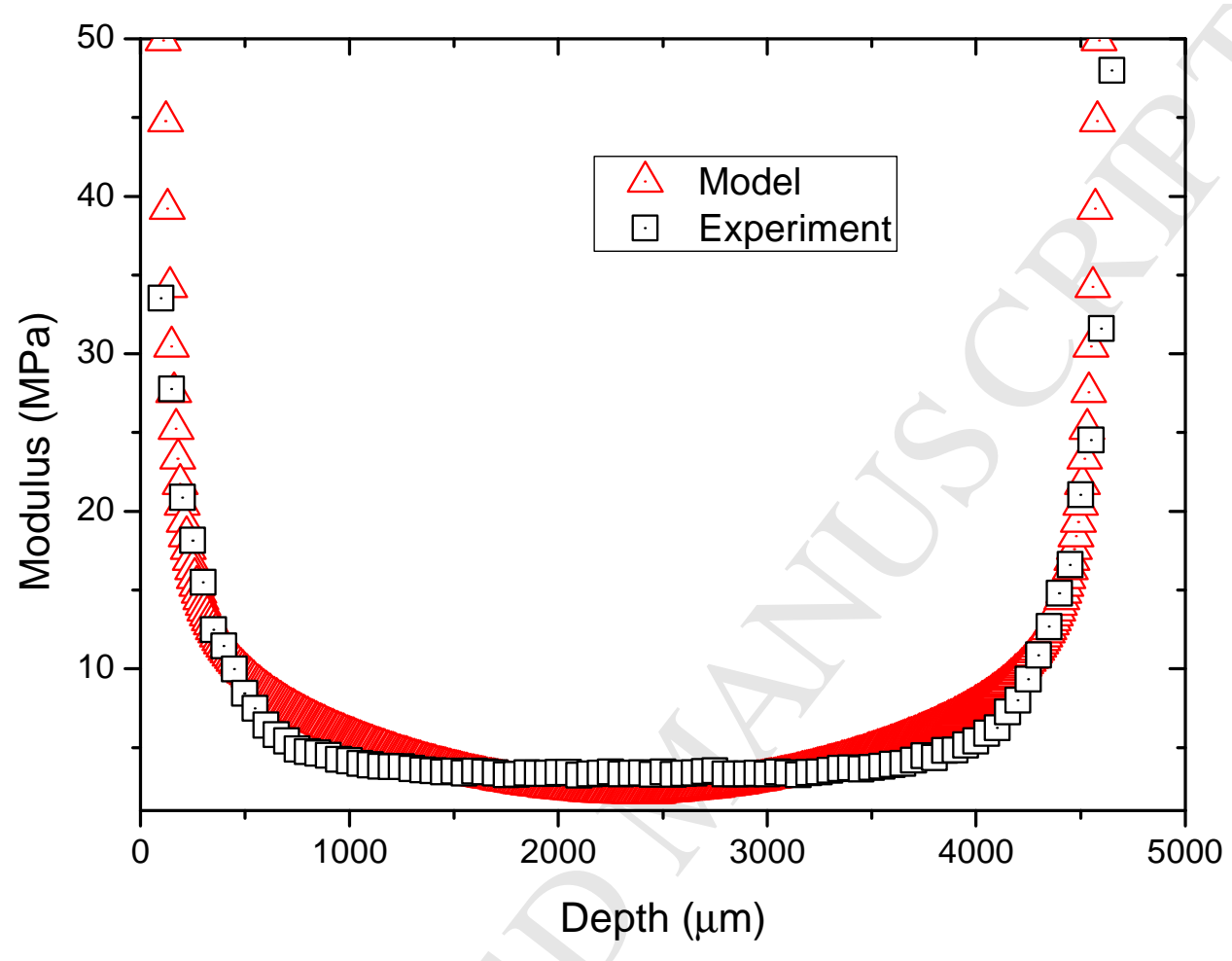

Figure 11: Comparison between predicted and measured modulus profile for a material cross-section after 6 days of ageing at $120^{\circ} \mathrm{C}$.

Overall, the predicted modulus profile is in good agreement with the measured modulus data, yet the transition between the oxidized skin and the core for the actual aged material appears slightly more abrupt than the simulation predicts. A possible cause of discrepancy could be a change in oxygen diffusivity due to crosslinking. A decrease of $P$ in the superficial layer would increase its protective role and may explain the observed difference. 


\section{Conclusions}

The oxidation of a sulfur vulcanized polychloroprene has been studied in the $60^{\circ} \mathrm{C}$ to $140^{\circ} \mathrm{C}$ range, most importantly by measurements of the double bond changes using IR and by the quasi equilibrium elastic (Young's) modulus. These measurements were performed on thin films where oxidation is almost homogeneous and in thick $(4.8 \mathrm{~mm})$ samples where oxidation is diffusion controlled. A kinetic model was established on the basis of 11 elementary reactions among which 7 correspond to the standard mechanistic scheme for oxidation propagated by hydrogen abstraction, 2 correspond to radical additions to double bonds and 2 correspond to the (relatively strong) stabilizing effect of sulfur containing species originating from the vulcanization process. An oxygen diffusion term was incorporated into the kinetic equations in order to predict the concentration of every reactive species or reaction product at every time and every location across the sample thickness. Considering that a temperature independent fraction $(\tau=0.35)$ of radical additions leads to crosslink formation and that oxidation of sulfur bridges leads to the disappearance of crosslinks, and using the basic theory of rubber elasticity to calculate the modulus from the crosslink density, the kinetic model allows the prediction at any time of the modulus for thin films and of the modulus profile for thick samples. Despite some limitations, the model predictions are in relatively good agreement with experimental results. This model, in its present state, represents a good point of departure for further investigations. 


\section{References}

[1] Tobolsky, A. V., \& Mercurio, A. (1959). Oxidative degradation of polydiene vulcanizates. Journal of Applied Polymer Science, 2(5), 186-188.

[2] Bolland, J. L., \& Gee, G. (1946). Kinetic studies in the chemistry of rubber and related materials. II. The kinetics of oxidation of unconjugated olefins. Transactions of the Faraday Society, 42, 236-243. [3] Tobolsky, A. V., Metz, D. J., \& Mesrobian, R. B. (1950). Low Temperature Autoxidation of Hydrocarbons: the Phenomenon of Maximum Rates1, 2.Journal of the American Chemical Society, 72(5), 1942-1952.

[4] Rincon-Rubio, L. M., Fayolle, B., Audouin, L., \& Verdu, J. (2001). A general solution of the closedloop kinetic scheme for the thermal oxidation of polypropylene. Polymer Degradation and Stability, 74(1), 177-188.

[5] Colin, X., Audouin, L., \& Verdu, J. (2007). Kinetic modelling of the thermal oxidation of polyisoprene elastomers. Part 3: Oxidation induced changes of elastic properties. Polymer degradation and stability, 92(5), 906-914.

[6] Coquillat, M., Verdu, J., Colin, X., Audouin, L., \& Nevière, R. (2007). Thermal oxidation of polybutadiene. Part 1: Effect of temperature, oxygen pressure and sample thickness on the thermal oxidation of hydroxyl-terminated polybutadiene. Polymer degradation and stability, 92(7), 1326-1333. [7] Gillen, K. T., Wise, J., \& Clough, R. L. (1995). General solution for the basic autoxidation scheme. Polymer Degradation and Stability, 47(1), 149-161.

[8] Gillen, K. T., \& Clough, R. L. (1992). Rigorous experimental confirmation of a theoretical model for diffusion-limited oxidation. Polymer, 33(20), 4358-4365.

[9] J Wise, KT Gillen, and RL Clough. Quantitative model for the time development of diffusion-limited oxidation profiles. Polymer, 38(8):1929-1944, 1997

[10] Celina, M., Wise, J., Ottesen, D. K., Gillen, K. T., \& Clough, R. L. (1998). Oxidation profiles of thermally aged nitrile rubber. Polymer degradation and stability, 60(2), 493-504.

[11] Celina, M., Wise, J., Ottesen, D. K., Gillen, K. T., \& Clough, R. L. (2000). Correlation of chemical and mechanical property changes during oxidative degradation of neoprene. Polymer degradation and Stability, 68(2), 171-184.

[12] Le Gac, P. Y., Roux, G., Verdu, J., Davies, P., \& Fayolle, B. (2014). Oxidation of unvulcanized, unstabilized polychloroprene: A kinetic study. Polymer Degradation and Stability, 109, 175-183.

[13] Hofmann, W. (1989). Rubber technology handbook. Hanser Publishers. Distributed in the USA by Oxford University Press.

[14] Delor, F., Lacoste, J., Lemaire, J., Barrois-Oudin, N., \& Cardinet, C. (1996). Photo-and thermal ageing of polychloroprene: effect of carbon black and crosslinking. Polymer Degradation and Stability, 53(3), 361-369.

[15] Celina, M. C. (2013). Review of polymer oxidation and its relationship with materials performance and lifetime prediction. Polymer Degradation and Stability, 98(12), 2419-2429.

[16] Gillen, K. T., Clough, R. L., \& Quintana, C. A. (1987). Modulus profiling of polymers. Polymer degradation and stability, 17(1), 31-47. 
[17] Shelton, J. R. (1957). Aging and oxidation of elastomers. Rubber Chemistry and Technology, 30(5), 1251-1290.

[18] Colin, X., Audouin, L., Verdu, J., \& Le Huy, M. (2007). Kinetic modelling of the thermal oxidation of polyisoprene elastomers. Part 2: effect of sulfur vulcanization on mass changes and thickness distribution of oxidation products during thermal oxidation. Polymer degradation and stability, 92(5), 898-905.

[19] Le Gac, P. Y., Broudin, M., Roux, G., Verdu, J., Davies, P., \& Fayolle, B. (2014). Role of strain induced crystallization and oxidative crosslinking in fracture properties of rubbers. Polymer, 55(10), 2535-2542.

[20] Coquillat, M., Verdu, J., Colin, X., Audouin, L., \& Neviere, R. (2007). Thermal oxidation of polybutadiene. Part 2: Mechanistic and kinetic schemes for additive-free non-crosslinked polybutadiene. Polymer degradation and stability,92(7), 1334-1342.

[21] Richaud, E., Monchy-Leroy, C., Colin, X., Audouin, L., \& Verdu, J. (2009). Kinetic modelling of stabilization coupled with stabilizer loss by evaporation. Case of dithioester stabilized polyethylene. Polymer Degradation and Stability,94(11), 2004-2014.

[22] Djouani, F., Richaud, E., Fayolle, B., \& Verdu, J. (2011). Modelling of thermal oxidation of phosphite stabilized polyethylene. Polymer Degradation and Stability, 96(7), 1349-1360.

[23] Van Krevelen, D. W., \& Te Nijenhuis, K. (2009). Properties of polymers: their correlation with chemical structure; their numerical estimation and prediction from additive group contributions. Elsevier. Chap 18, p660 